\title{
Entrevista com Maria Leonor Botelho
}

Flávia Mattos

Universidade Federal do Rio de Janeiro (UFRJ), Brasil

flaviamattosbr@gmail.com
DOI: https://doi.org/10.18472/cvt.21n3.2021.1985 Redalyc: https://www.redalyc.org/articulo.oa? id $=115469516009$

\section{Primeiras palavras...}

Nossa entrevistada desta edição é Maria Leonor Botelho, nascida em 1979 na cidade do Porto, doutora em História da Arte Portuguesa. Nosso primeiro encontro aconteceu no Brasil, em Juiz de Fora, Minas Gerais, durante o Congresso Internacional "Gestão dos Patrimônios da Humanidade Urbanos: desafios e riscos de preservação”, em 2019, quando Leonor, a convite dos professores Rodrigo Christofoletti e Marcos Olender, do Laboratório de Patrimônios Culturais - LAPA, da Universidade Federal de Juiz de Fora - UFJF, compartilhou suas experiências como pesquisadora do Centro de Investigação Transdisciplinar Cultura, Espaço e Memória - CITCEM/FLUP e docente do Departamento de Ciências e Técnicas do Patrimônio da Faculdade de Letras, da Universidade do Porto, onde também atua como diretora do Curso de Mestrado em História da Arte, Patrimônio e Cultura Visual. Lembro-me que foi ainda na fila do refeitório, no intervalo entre as sessões do Congresso, que Leonor começou a me contar sobre as linhas de pesquisa em que atuava e sobre uma edição da revista "CEM/Cultura, Espaço e Memória" que estava organizando na ocasião. Com interesses de investigação voltados à gestão do patrimônio, ao digital heritage, à história urbana e à historiografia da arquitetura da época românica, Leonor circula pelas leituras contemporâneas dos estudos de patrimônio, tem atenção especial aos processos de produção e transmissão do conhecimento e, a cada dia, vem tecendo e ampliando vínculos colaborativos, no seu país, e em âmbito internacional - em publicações, ao nível editorial, no campo da orientação e na participação em júris, tornando sua atuação profissional ainda mais fecunda. Uma de suas produções mais recentes é o livro "Relações Internacionais e Patrimônio. Retalhos em tempos de Pluralidade”, da Série de Estudos Latino-Americanos, Springer, que organizou juntamente com o professor Christololetti. Já desenvolveu uma série de projetos de extensão em sítios patrimoniais em Portugal, entre outras atuações, como a co-tradução da London Charter para o português. Esta entrevista, realizada à distância, por correspondências, parte do desejo de conhecer mais a fundo o seu percurso, suas ideias e projeções para o campo do patrimônio. Espero que os leitores se nutram com sua escrita reflexiva, suas experiências, seu engajamento e referenciais, e possamos ampliar o circuito de trocas e debates. E que os encontros presenciais - tão marcantes e enriquecedores - nunca deixem de fazer parte da nossa vivência acadêmica.

Flávia Mattos 


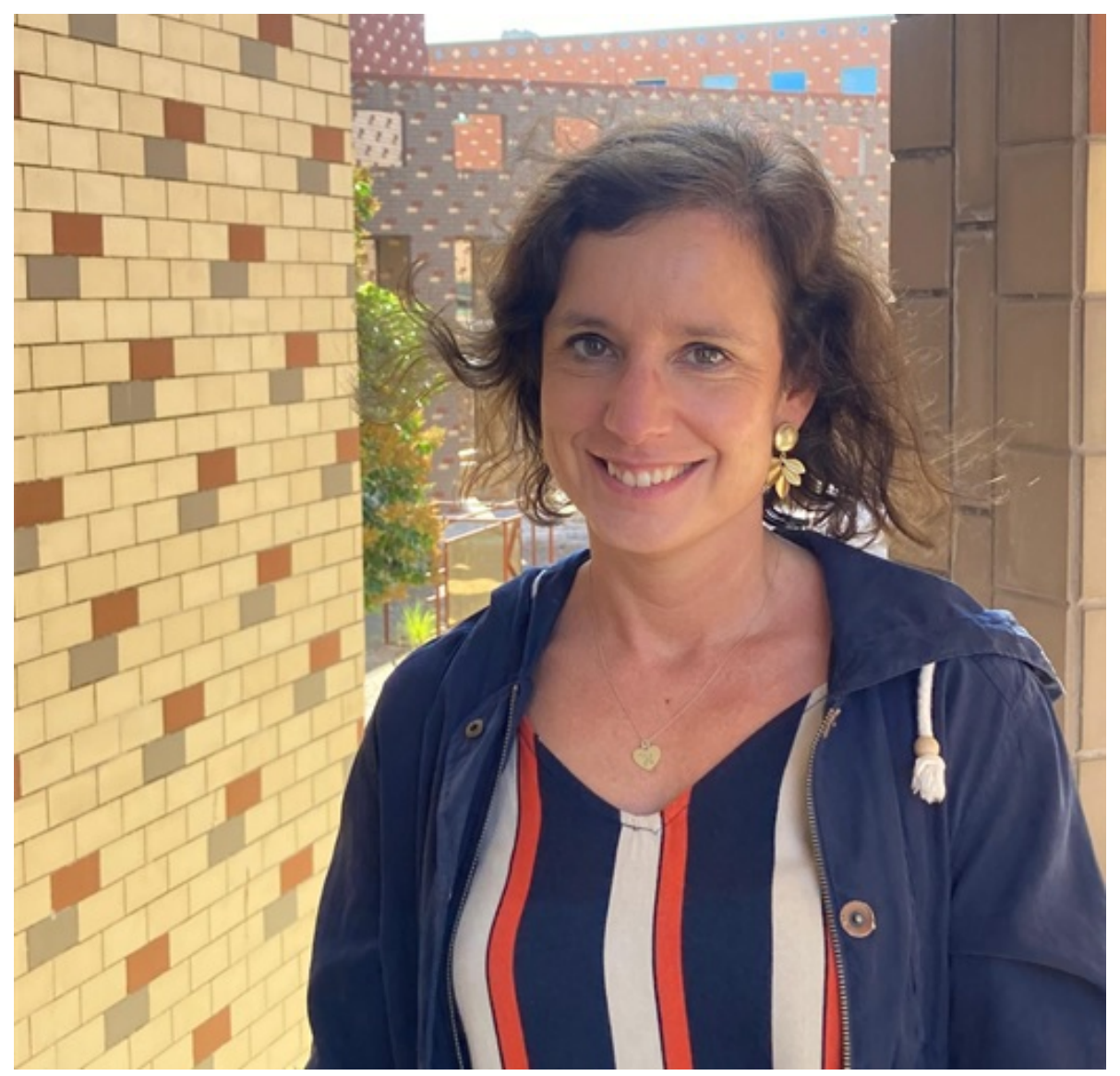

Maria Leonor Botelho. Local: Faculdade de Letras da Universidade do Porto Ano: 2021. Foto: Cátia Oliveira.

\section{1) Ao longo de sua trajetória acadêmica, quais foram suas principais indagaçóes de pesquisa? Por quais abordagens transita?}

Foi numa viagem ao estrangeiro, ainda jovem, que terá surgido a minha questão de partida e que definitivamente ditou o meu percurso académico. Após uma série de visitas, cheguei a um museu (Museu da Marinha de Greenwich) e, fascinada com a forma como eram mediados os seus conteúdos, questionei-me por que não se explorava mais aquela metodologia. À época não se encontravam ainda muitas abordagens de mediação em que o público pudesse interagir com os objetos em contexto museológico ou patrimonial. $\mathrm{E}$ a questão das experiências digitais ainda nem se quer se colocava... o paradigma ainda era outro. Cedo me apercebi da necessidade de investir na comunicação e, mais do que isso, na forma como se comunica. Hoje, procuro trabalhar esta questão da comunicação com os meus alunos. Em Estudos de Património é tão importante aquilo que se transmite (conteúdo) como o meio que se utiliza (forma). Claro que só muitos anos mais tarde, no meu percurso, é que esta inquietação veio à tona e, posso dizer, através da minha atividade docente encontrei o laboratório para testar modelos e práticas. Se foi esta inquietação que me levou a uma licenciatura em História, variante de História da Arte (Flup, 2001), por acreditar ser significante o conhecimento contextualizado, crítico e comparado das manifestações materiais que a história nos legou, foi a preocupação com a sua preservação (ou modos de preservação) no tempo e com a sua gestão no presente, e para o futuro, que me fez optar pela realização de um Mestrado em Arte, Património e Restauro (Flul, 2004) [1]. Através da investigação então realizada, e que de certa forma lançou as pistas para aquilo que viria depois a ser o meu Doutoramento em História da Arte Portuguesa (Flup, 2011), comecei a tentar entender 
que aquilo que herdamos hoje e que reconhecemos de Património resulta não só do conhecimento que se tem sobre os bens patrimoniais, das escolhas do que salvaguardar realizadas num dado momento histórico, mas também da forma como se foi optando por conservá-lo e, por consequência, transmiti-lo. E entramos no campo dos valores prospetivos do Património...

\section{2) Como você se situa e autodefine nos estudos de patrimônio?}

Fazer uma autodefinição do meu posicionamento no campo dos estudos de património é um grande desafio! Primeiro porque acredito que esta área disciplinar passou nos últimos anos por um processo de alargamento concetual, geográfico e cronológico (tal como F. Choay tão bem antecipou)[2], como também estamos a viver agora um momento de questionamento profundo. Os estudos de património constituem um campo fascinante que requer rigor na instrução de qualquer processo de patrimonialização, na sua valorização e difusão. A minha atuação é balizada pelo meu papel enquanto investigadora e enquanto docente. E, usando uma terminologia muito própria deste campo de estudos, atuo como "ator" a partir de um lugar privilegiado que é o da Academia. Ora, enquanto docente e orientadora tenho a responsabilidade de transmitir a futuros atores a história desta disciplina e a forma como os vários momentos históricos reconheceram valores e atributos em bens que foram assim patrimonializados. E renovamos o ciclo quando selecionamos, patrimonializamos e valorizamos determinados bens em detrimento de outros... E por isso reconhecço aqui um certo sentido de missão nesta transmissão de conhecimento e ao formar estudantes em ensino graduado e pós-graduado. Cabe aos mais jovens, e àqueles que desenvolvem investigação pós-graduada no campo de estudos de património, revisitar o lugar dos bens na sociedade, desenvolver metodologias que permitam às comunidades uma participação ativa nos procesos de patrimonialização e, assim, trilhar novos caminhos. Acredito na valorização do património à escala local mediada por uma educação para o património desenhada com qualidade, recorrendo a instrumentos digitais mas procurando uma participação ativa dos cidadãos, independentemente da sua literacia histórica, artística e, mesmo, patrimonial. Cada vez mais o paradigma é, e deve ser, o das ações "bottom-up" inclusivas e promovendo a acessibilidade, no respeito pela diversidade etária, cultural e social. Um autor que para mim é uma referência, Carlos Alberto Ferreira de Almeida, afirmou de forma muito clara que «o Património tem de ser aceite e estimado e não apenas protegido. Ele não é uma simples reserva, mas deverá ser, antes, uma abraçável aceitação» (Almeida, 1998: 20)[3].

\section{3) Qual a importância que o estudo da historiografia da arquitetura da época românica em Portugal teve na sua forma de abordar o patrimônio cultural português?}

O estudo da historiografia da arquitetura da época românica, mote do meu Doutoramento[4], foi fundamental para o meu percurso. A minha investigação teve como ponto de partida a seguinte questão: de que modo o conhecimento que se tinha num dado momento sobre o românico impactou (ou foi consequente) nas acções de restauro realizadas sobre os edifícios intervencionados no século XX? Ou seja, interessou-me perceber as tendências historiográficas, as ruturas e as permanências, para poder compreender o que em determinados momentos chave se entendia como românico português. $O$ estudo de obras publicadas durante quase mais de um século fez-me percecionar quem eram os principais autores, quem efetivamente trouxe novidade de pensamento e quais destes passaram ao papel de atores na história do património português. A verdade é que foi evidente o comprometimento de muitos autores que se assumiram como "cruzados" numa luta pela salvaguarda de um conjunto significativo de edifícios (particularmente durante as décadas de 1930 e 1940). Daqui foi natural a passagem para o estudo aturado das intervenções de restauro realizadas durante o século XX na arquitetura românica e a confirmação de que os estudos sobre arquitetura medieval, em Portugal e no estrangeiro, têm necessariamente de considerar este momento 
da história dos edifícios. De facto, se por um lado neste quadro cronológico e concetual se transformou a sua imagem de uma forma evidente, por outro devemos a estas ações a permanência física e material de uma parte significativa da arquitetura desta época. A consciência desta realidade ensinou-me que temos de respeitar a forma como as várias épocas abordam o património e, acima de tudo, compreender que as ações de salvaguarda, as destruiçóes e as transformações resultam de um conjunto concreto de circunstacialismos histórico-geográficos e, acima de tudo, de uma dada cultura patrimonial. Ou seja, de um particular processo de reconhecimento que não deixa de ser comprometido.

\section{4) Como você percebe o engajamento dos portugueses, particularmente dos jovens, em relação ao interesse em conhecer, produzir, conservar e interpretar o patrimônio cultural em Portugal?}

Esta questão é muito interessante! Em primeiro lugar devo notar uma maior procura, nos últimos anos, ao nível da formação graduada e pós-graduada no campo das ciências do património. A minha percepção, que decorre acima de tudo da minha condição de docente e tratando o património a partir da área científica da História da Arte, é que os jovens estão não só cada vez mais sensibilizados para as tarefas fundamentais da gestão do património cultural como também reúnem um conjunto de competências criativas que devem ser potenciadas a este nível. Cabe a estes um papel ativo ao nível da comunicação do património cultural através das plataformas digitais e da criação de instrumentos alternativos que convidem novos públicos a uma participação ativa e, até, inclusiva. Através de projetos pedagógicos que tive oportunidade de desenvolver, conjuntamente com outros colegas, pude também verificar como os mais jovens se comprometem e desenvolvem propostas inovadoras. E como geração "digitalis" os mais jovens acompanham aquilo que se produz no exterior, participam de encontros digitais e procuram estabelecer redes de contacto. Quero acreditar ainda que nos vão surpreender muito! E mais, nós próprios já lhes estamos a transmitir um legado patrimonial, a passar conhecimentos e experiências ao nível da sua gestão. Caberá aos jovens que agora se formam um papel idêntico num futuro próximo, enquanto atores responsáveis por um legado que irão transmitir às gerações vindouras.

\section{5) Quais foram esses projetos pedagógicos? Qual deles você destacaria para se pensar na participação ativa/inclusiva?}

É importante falar desta experiência num grau como o da da formação base que é a Licenciatura. Para lá da fundamental aquisição de conhecimento, o desenvolvimento da aprendizagem através da exploração das competências parece-me fundamental. E porque acredito nisso, procuro que os estudantes façam trabalhos que potenciem o seu conhecimento do objetivo artístico e lhes permitam explorar a comunicação do objeto artístico enquanto objeto patrimonial, que testem diferentes modelos e suportes de comunicação de um conhecimento científico que se quer rigoroso. Acima de tudo, é importante que os estudantes, futuros atores no campo do património, percebam que é preciso ajustar os conteúdos que dominam a diferentes objetivos e vários tipos de suporte e de público. Defendo o trabalho colaborativo entre estudantes (também como laboratório de aprendizagem ao nível das chamadas soft skills e potenciando as chamadas competências de aprendizagem do século XXI[5]) pelos desafios que este lhes cria na dinâmica entre pares, na discussão de ideias e numa aprendizagem fundamental que é a da gestão de recursos. $\mathrm{O}$ facto de deslocarmos os estudantes da sua zona de conforto tem-me mostrado os ganhos que estes podem vir a ter. Além disso, criam-se nos trabalhos de grupo pequenos laboratórios que permitem desenvolver embrióes daquilo que podem vir a ser produtos de comunicação potenciando a participação ativa do público (quando os estudantes desenvolvem trabalho para um público alvo tão concreto quanto o infantil mas sem infantilizar os conteúdos!) ou quando 
ensaiam parcerias com instituições ou refletem sobre a questão da difícil acessibilidade a um dado sítio, por exemplo. Tenho aprendido muito com os meus alunos! E o seu feedback tem sido incrível - para lá dos resultados alcançados, têm-me surpreendido (e se calhar a eles próprios) pela originalidade das suas próprias propostas. Se são vários projetos? Não sei! Talvez seja mais um projeto (ou missão) que abracei como docente, como se fosse um todo que se complementa através das partes.

\section{6) Qual o legado do projeto "Porto de Virtudes" e suas lições aprendidas? Conte-nos sobre essa experiência.}

O projeto "Porto de Virtudes[6]" foi desenvolvido no âmbito do Mestrado em História da Arte, Património e Cultura Visual da Faculdade de Letras da Universidade do Porto e mereceu um dos Prémios de Inovação Pedagógica da UP do ano 2017. Foi coordenado pela Prof. Lúcia Rosas, pelo Prof. Hugo Barreira e por mim. Com a colaboração de várias instituições como a Cooperativa Árvore e a Câmara Municipal do Porto foi possível implementar um projeto que teve na criação de uma exposição virtual na plataforma Google Arts \& Culture o seu elemento âncora. O maior ensinamento que retiro do projeto é que quando há comprometimento há bons resultados. O projeto foi desenhado para e pelos estudantes do Mestrado. Eles fizeram a investigação primária em torno da área urbana das Virtudes, interpretaram as fontes, fizeram a revisão da literatura, produziram conteúdos para a exposição virtual, para uma exposição física, para um e-book[7], desenharam visitas temáticas, que conduziram e, ainda, foram os responsáveis por todo o design gráfico do projeto. Descobriram-se vocações! Houve muito trabalho de bastidores, mas os resultados alcançados e a recepção do projeto por parte das entidades e do público mostraram-nos que é fundamental "aprender, fazendo" (learning by doing). O "Porto de Virtudes" foi um laboratório pedagógico, um laboratório de aprendizagem, um laboratório de investigação e um laboratório de comunicação. Lançou pistas de investigação futuras. Foi uma verdadeira e complexa aprendizagem, acima de tudo.

\section{7) Quais as reflexões que acompanham o uso de novas modalidades digitais aplicadas ao patrimônio na atualidade? Quais os campos de investigação que se abrem?}

O contexto pandémico atual veio acelerar uma discussão que já se fazia sentir no campo dos estudos de património. A comunicação digital já era uma evidência deste século XXI. As páginas web dos museus, dos sítios patrimoniais e das instituições de referência já estavam bem presentes no nosso dia a dia. Nos últimos anos multiplicaram-se os recursos digitais em torno de projetos de investigação, bem como plataformas e bases de dados. As redes sociais vieram incrementar a comunicação ativa das instituições e, desde março de 2020, estiveram na linha da frente na mediação da comunicação entre os espaços patrimoniais que se viram de portas fechadas e sem público... A questão da mediação digital com os públicos e as comunidades é, efetivamente, um campo em expansão, mas que não deve substituir a mediação direta e presencial. Agora, há que regressar aos sítios patrimoniais e aos museus. Há que mediar para convidar o público a visitar e sensibilizar as comunidades a participar, de forma ativa e inclusiva. As experiências imersivas que as novas tecnologias digitais proporcionam, sejam quais forem, nunca irão substituir a experiência direta com os mesmos. Os conteúdos que as novas tecnologias podem proporcionar no campo do património devem ser desenvolvidos com rigor e transparência. Além disso, devem ser um convite a uma visita física, e inclusive complementar a mesma, pois devem acrescentar conhecimento, devem abrir caminho à partilha e à discussão. Foram já desenvolvidos ou estão em desenvolvimento projetos, em diversos ciclos de estudo, que me fazem pensar (e discutir conjuntamente com os estudantes) sobre estas questões e que constituem oportunidades para a produção de conhecimento em níveis mais avançados. Não posso deixar de referir que o trabalho de orientação de Doutoramentos e de Mestrados é por si só uma excelente oportunidade para trabalhar questões 
ligadas à mediação patrimonial, à sua adequação às várias escalas e a diferentes de tipo de comunidades (e públicos), às novas tendências e metodologias aplicadas à educação para o património ou, inclusive, à sua vertente mais digital. Foi neste contexto de orientação, por exemplo, que tive oportunidade de contactar com a Carta de Londres e, num trabalho conjunto com um estudante, trabalhar na sua tradução oficial portuguesa! Este é um campo que se tem mostrado muito ativo ao nível da doutrina internacional, mas também ao nível da ação de redes de investigação e de projetos internacionais. A digitalização do património, móvel e imóvel, é efetivamente uma realidade (e uma oportunidade que as linhas de financiamento e os call científicos têm vindo a confirmar), quer como ferramenta de investigação por si só enquanto campo disciplinar, quer ainda enquanto instrumento de mediação com o público (realidade que no quadro da pandemia COVID-19 se veio a explorar ainda mais). Voltando à questão, outros trabalhos desenvolvidos com estudantes têm resultado em exposições virtuais e outros há que, em curso, irão seguramente trazer novos dados ao nível da reflexão em torno do património como processo.

\section{8) De que maneira você aborda essas questões da mediação e transmissão de conteúdos com os estudantes?}

A minha aproximação ao digital, a partir dos estudos de património, foi muito curiosa. Como já pude mencionar, a questão da mediação e da transmissão dos conteúdos tem sido uma constante na minha atividade docente. Quando comecei a lecionar a unidade curricular de Gestão de Património, na Licenciatura em História da Arte, deparei-me com o problema de que trabalho prático desenvolver com os estudantes. Surgiu a ideia de criar pequenas exposições virtuais e a partir destas desenhar uma proposta de programa de mediação. A ideia da aprendizagem como laboratório (ou do "learning by doing") está subjacente e as propostas que os estudantes têm apresentado têm sido surpreendentes e reveladoras das capacidades que esta geração "digitalis" tem. Mas o que importa aqui é o exercício que vai desde a escolha do tema, dos objetos a apresentar, da construção e do tom da narrativa, da apresentação visual dos conteúdos e das diversas propostas de mediação que desenvolvem num trabalho que tem de ser necessariamente colaborativo. Num outro contexto, a oportunidade de desenvolver conteúdos para a Google Arts \& Culture tem sido fundamental. O projeto "Porto de Virtudes" vem na sequência de experiências anteriores e depois deste já se desenvolveram outros[8]. A criação de conteúdos para uma exposição virtual é muito exigente (Botelho, et. All., 2018). É necessário criar um conhecimento sólido sobre os temas para se conseguir desenhar uma dupla narrativa, a visual e a escrita. Ambas se complementam, mas têm, também, de funcionar de forma autónoma e com a sua própria independência.

\section{9) Como trabalhar a mediação de forma aliada a uma educação patrimonial?}

A mediação do património e a educação patrimonial (ou educação para o património) andam lado a lado. Podemos ter acesso a instrumentos de comunicação únicos, a conteúdos inéditos e até a bens patrimoniais excecionais, mas se a mediação não for acessível, não vamos alcançar os resultados desejáveis. Enquanto documentos orientadores e operativos, a Convenção Quadro do Conselho da Europa relativa ao valor do Património Cultural para a Sociedade (2005) e a mais recente Carta de Porto Santo (2021)[9], atestam a importância deste campo de reflexão e de ação. Recorrendo mais uma vez à minha experiência enquanto docente, através do trabalho de proximidade com comunidades tenho verificado que a educação para o património é um trabalho constante e que tem de se ajustar às várias faixas etárias, sociais e culturais. Aqui temos de dar o salto, nem sempre linear e muito menos imediato, entre a educação formal (com que lidamos diariamente) para a educação não-formal. Primeiro porque na maior parte dos casos lidamos ou com património imaterial ou com bens não protegidos. Depois, porque nem sempre o nível de literacia das 
comunidades ou a faixa etária, que se torna o nosso público, nos permite utilizar uma linguagem erudita, pejada de conceitos particularizados. A mediação deve ser entendida como um exercício de questionamentos constantes: O que vou transmitir? Por que e como o vou fazer? E para quem? Estas premissas têm de ser consideradas a todos os níveis. Só assim a investigação científica em torno do património faz sentido pois tem de se tornar acessível e ser um efetivo contributo para a sociedade, sendo ao mesmo tempo inclusiva. É um desafio efetivo ao nível da transmissão de conhecimentos. As universidades são stakeholders fundamentais na gestão do património aos mais diversos níveis. Se por um lado devem-se afirmar como atores ativos junto dos decisores políticos e institucionais pelo know how produzido, devem também ser mediadores junto dos públicos tornando a produção de conhecimento mais acessível, partilhando-a, e dando-lhe um lugar útil na sociedade e afirmar, assim, o valor económico do património. Não há um modelo único! Cada caso é um caso, cada contexto tem as suas particularidades e cada projeto as suas características e vicissitudes

\section{0) Quais os desafios a serem enfrentados no campo da mediação do patrimônio em Portugal?}

No âmbito da mediação do património há muito caminho, ou caminhos, a percorrer. Uma coisa é criar conteúdos, para serem consultáveis num app ou num roteiro digital, outra, é transmitir os mesmos num espaço interpretativo de um dado sítio patrimonial. Depois há que ter consciência que, e particularmente no primeiro caso, nem todos têm os equipamentos apropriados para o acesso digital ao património. Apesar da disseminação do digital e do seu papel fundamental nos campos da mediação do património, carecemos ainda de um conjunto de políticas que nos permitam balizar a nossa ação. Já existem reflexões fundamentais ao nível da preservação dos dados produzidos no contexto do património digital (digital heritage), bem como ao nível da criação de conteúdos no campo da visualização computorizada do património (de que a Carta de Londres, os Princípios de Sevilha ou a Carta de Berlim são os mais significativos testemunhos). Mas há ainda muito a fazer no campo da discussão no âmbito daquilo que poderíamos chamar de "boas práticas" no campo da mediação patrimonial entendida enquanto processo que vai desde a documentação sobre o bem até à sua comunicação inclusiva e acessível, respeitando diferentes níveis de literacia cultural, diferenças sociais e a diversidade cultural que a Recomendação de Nara (ICOMOS, 1994) tão bem clamou e a de Nara+20 (ICOMOS, 2014) já procura atualizar. E há que considerar que há um grande hiato entre as gerações mais velhas e aquela que chamamos de geração "digitalis"... nem todos dominam as tecnologias, nem todos têm os recursos para que as mesmas lhes sejam acessíveis e nem todos conseguem compreender os conteúdos que as mesmas, no campo patrimonial, podem transmitir. Há que haver bom senso e calibrar.

\section{1) O que podemos aprender sobre gestão do patrimônio nas experiências portuguesas? Em particular, o que a experiência da inscrição do centro histórico do Porto como patrimônio mundial, em 1996, nos revela em relação aos desafios a enfrentar?}

Naturalmente que o Centro Histórico do Porto tem sido um excelente laboratório de investigação e é um laboratório de aprendizagem permanente. A sua inscrição na lista do Património Mundial em 1996 foi fundamental para a realização de uma série de transformações na malha urbana e edificada da cidade. A cidade do Porto de 1996 é muito diferente da cidade de 2021! É uma cidade requalificada (e para lá do seu Centro Histórico), é uma cidade com mais equipamentos culturais e com muitos mais turistas. Não podemos negar o impacte da brand UNESCO e o que esta trouxe em termos de investimento ao nível da reabilitação da malha edificada, do crescimento exponencial de equipamentos hoteleiros e infra-estruturais. Claro que podíamos discutir aqui uma série de questões que têm sido trazidas à praça pública como a da gentrificação, do fachadismo ou da turistificação. Quando os meus alunos me pedem uma opinião pessoal costumo dizer que há 
que medir prós e contras e, acima de tudo, procurar compreender as opções tomadas nos seus vários contextos. Há que perceber que nas últimas décadas se ensaiaram distintas abordagens ao nível da requalificação e que estas foram sendo pautadas por paradigmas de atuação diferentes. Por exemplo, a requalificação do quarteirão das Cardosas respondeu a objetivos totalmente diferentes daqueles que têm estado presente na operação em torno dos quarteirões da Sé ou até da zona de Santa Clara (Albuquerque \& Botelho, 2017)[10]. Se numa ação a gentrificação é uma realidade, nas outras identifica-se a preocupação com a continuidade do tecido social recorrendo a diferentes modelos de ação. No campo da gestão do património é difícil ser-se consensual e, como tão bem notou Choay, a "escolha" implica sempre uma "perda".

\section{2) Quais os projetos que te motivam na atualidade e a que temas e ações você pretende se dedicar nos próximos anos?}

Nos últimos tempos algo me tem inquietado no campo dos estudos de património... Há umas décadas já, F. Choay[11] alertou-nos para a questão da inflação do património, para a sua massificação e turistificação. Este campo de estudos tem conhecido um imenso investimento ao nível da investigação teórica que atesta a sua especificidade e o uso cada vez mais fino dos conceitos, mas também um outro planeamento e uma maior estratégia ao nível das ações práticas. Falar sobre património e sobre as suas questões tem de ser feito com propriedade, com domínio dos conceitos e das suas mutações no tempo longo. A acção em planeamento exige que se considere a sua sustentabilidade (aos mais diversos níveis), a acessibilidade, a inclusão, mas, ao mesmo tempo, a sua constante atualização. Cada vez mais estou alerta para a questão do património enquanto processo, resultante de um reconhecimento de atributos e sequentemente de valores. O património resulta de um reconhecimento que está no sujeito. Ora, isto conduz à criação de diferentes interpretações sobre o bem patrimonializado e, logo, a diferentes apresentações do mesmo. Cada vez mais subscrevo a ideia fundadora de Laurajane Smith (2006) [12] de património enquanto processo. Estas questões, de ordem mais concetual, conduzem-me à minha inquietação inicial, a da mediação. Quer esta seja feita sob a forma de uma exposição virtual ou física, quer sob a forma de um roteiro ou de um catálogo, ou inclusive de um programa audiovisual, prevalecerá sempre a interpretação que o sujeito, enquanto ator no processo de patrimonialização tem sobre um dado objeto, ou conjunto de objetos, e sobre os quais vai construir a sua narrativa. E esta narrativa tem de estar em constante atualização. O storytelling aplicado aos estudos de património tem sido, efetivamente, uma das minhas maiores inquietações. A "história" que contamos tem de se ajustar a diferentes recetores (e.g. turísticos, pedagógicos, institucionais), a diversas faixas etárias e a diferentes objetivos. Os mesmos conteúdos podem ser potenciados de forma muito diferente. E isso não significa que em momento algum se perca rigor científico! Sim, este é um dos caminhos que mais gostava de (continuar) a explorar nos próximos anos. 


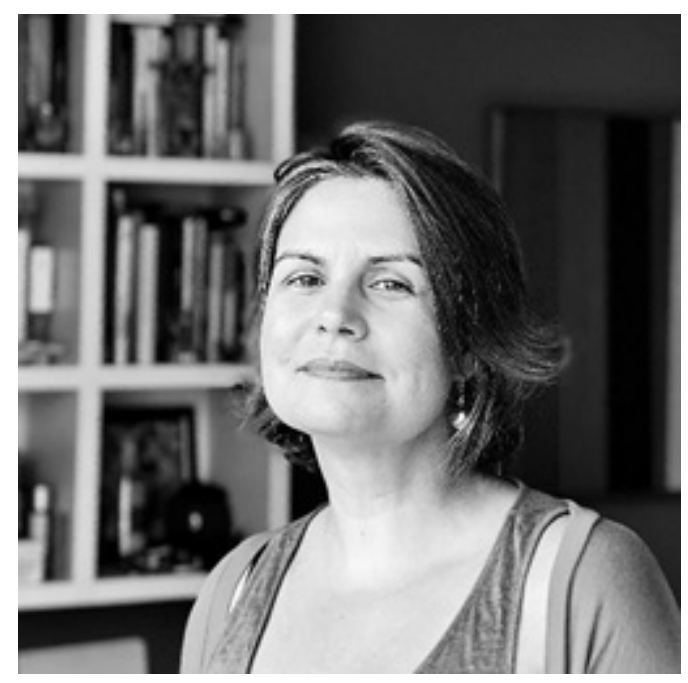

Flávia Mattos é psicóloga, doutora em Engenharia de Produção pela COPPE/ UFRJ e editora científica do Caderno Virtual de Turismo - Tempespaço (CVT).

\section{Notas}

[1]Ver BOTELHO, M., L. (2006). A Sé do Porto no século XX. (pp. 277 ) Lisboa: Livros Horizonte.

[2]CHOAY, Françoise. Património e Mundialização, Editora Licorne, 2010. ISBN: 978-972-8661-61-8

[3]Cf. ALMEIDA, Carlos Alberto Ferreira de. Património : o seu entendimento e a sua gestão. 2a ed . Porto : Etnos, 1998. ISBN 972-96935-3-6.

[4]Ver BOTELHO, M. L., (2013). A Historiografia da Arquitectura da Época Românica em Portugal (1870-2010). (1 ed., , pp. 866 ) Lisboa: Fundação Calouste Gulbenkian.

[5]Cfr. Twenty-first century skills | International Bureau of Education (unesco.org)

[6]Cfr. Um "Porto de Virtudes" em exposição, eBook e visitas temáticas - YouTube

[7]Sobre esse projeto ver BOTELHO, M. L., \& ROSAS, L. (2021). The experience of managing the city of Porto as a World Heritage Site: how to teach and how to learn. In Christofoletti, Rodrigo , \& Olender, Marcos, World heritage patinas: actions, alerts and risks. (pp. 179-196). Cham: Springer.

[8]Vd. Faculdade de Letras da Universidade do Porto, Porto, Portugal - Google Arts \& Culture

[9]Presidência Portuguesa do Conselho da União Europeia (2021). Carta de Porto Santo. CARTA DE PORTO SANTO (Acessível em: culturaportugal.gov.pt).

[10]Ver Ana Rita Albuquerque et Maria Leonor Botelho, « Repenser les frontières des paysages urbains historiques. Pratiques et discours sur la ville de Porto », Culture \& Musées [En ligne], 33 |2019, mis en ligne le 19 novembre 2019, consulté le 16 novembre 2021. URL : http://journals.openedition.org/culturemusees/3102; DOI : https://doi.org/10.4000/culturemusees.3102

[11]CHOAY, Françoise. As questões do património : antologia para um combate. Lisboa : Edições 70, 2011. (Arte e comunicação). ISBN 978-972-44-1624-3.

[12]SMITH, Laurajane (2006), Uses of Heritage. New York: Routledge. 